\title{
Auditing and Re-auditing Nursing Care for Children Undergoing Central Venous Line Insertion in Pediatric Intensive Care Unit
}

\author{
Wafaa Mahmoud Mohamed, Azza Ahmed Altayeb, Nahed Thabet Mohamed \& Amal Abdrbou Hussein. \\ Nursing specialist in Almbra Hospital of Assiut health insurance, Egypt. \\ Professor of Pediatrics, Faculty of Medicine, Assiut University, Egypt \\ Assistant Professor of Pediatric and premature Nursing, Faculty of Nursing, Assiut University, Egypt \\ Lecturer of Pediatric and premature Nursing, Faculty of Nursing, Assiut University, Egypt.
}

\begin{abstract}
Aim: The aim was to audit and re-audit nursing care for children undergoing central venous line insertion in Pediatric Intensive Care Unit. Design: A quasi-experimental research design was used for the present study. Setting: The study was carried out at Pediatric Intensive Care Unit, Assiut University Children Hospital. Subjects: Convenience sample was obtained from nurses who gave care to all cases undergoing CVC insertion, working at the previous setting $(n=33)$. Data Collection Tools: Two tools were used: A structured interview questionnaire sheet and an indirect observation checklist. Results: The study revealed that a mild statistically significance differences were detected as regards CVC Insertion and medication administration ( $\mathrm{p}=0.373$ and 0.073 respectively), while the nurses' unsatisfactory practice concerning heparanization and dressing change declined during the re-auditing ( $\mathrm{p}=0.208$ and 0.422 respectively).Conclusion: Re-auditing of nurses caring for children undergoing central venous line insertion improved more significantly than auditing. Recommendations: Pediatric nurses should update their knowledge and practice through continued nursing education, training, and frequently attending seminars and conferences especially in infection control skills.
\end{abstract}

\section{Keywords: Auditing, Nursing Care, Children. Central Venous Line Insertion \& Pediatric Intensive Care Unit.}

\section{Introduction}

Central Venous Line (CVL), or "central line", describes a catheter placed usually in a neck (internal jugular vein) or groin (femoral vein), though it can also be placed in the liver (Trans hepatic), chest (subclavian), or back (Trans lumbar) veins. They are placed to provide long-term intravenous access or when attempts to achieve peripheral intravenous access have failed. Central venous lines can either be tunneled (buried under a portion of the skin) or nontunneled. Non-tunneled CVLs are usually in place for less than two weeks, whereas tunneled CVLs can be in place anywhere from two weeks to several months (Cooper, 2019). Different international health care agencies such as healthcare improvement (2011), WHO (2012), and Centers for Disease Control and Prevention (CDC) have targeted central venous catheter as a significant patient's safety issue (Ullman et al., 2013).

Central venous catheters play an important part in children's recovery as it can aid in diagnosis and treatment. In the acute care setting they provide a route for rapid and reliable intravenous administration of drugs, fluids, blood products and Parenteral Nutrition (PN) and may be used to monitor central venous pressure. They are also used for patients who require long-term IV access undergoing continuous/intermittent complex IV therapies such as

chemotherapy and blood sampling (American society of anesthesiologist, 2012).

Contraindications for central venous cannulation may be when the child has obstructed vein (e.g. clot) stenosis of the vein, raised intracranial pressure, severe coagulopathy, respiratory failure with high $\mathrm{fio}_{2}$ (fracture inspire $\mathrm{O}_{2}$ ), contaminated site, traumatized site (e.g. clavicle fracture), burned site and uncooperative awake child (Nickson, 2017).

Central venous catheters (CVC) are frequently used in intensive care. The possible complications of a central venous line include the following: mechanical complications such as arterial puncture, pneumothorax, hemothorax mediastinal hematoma and injury of adjacent nerves; and infectious complications or infection at local insertion site e.g. thrombophlebitis and endocarditis (Ahmad et al., 2016).

The nurse plays an important role in monitoring the patient and the catheter site. The patient's vital signs should be monitored and recorded, the sterile field must be maintained during any handling of the line and the line should be securely fastened to the patient (Zing et al., 2011). The dressing on the central venous site should be changed in accordance with hospital policy and procedures. It should always be changed using aseptic techniques and the catheter

Vol , (7) No , (17) June, 2019 
site must be closely observed. The nurse usually removes the catheter after the medical practitioner has given an instruction to do so. The patient should be informed, reassured and the procedure explained. The child should lie flat in bed with the feet of the bed elevated to prevent air emboli on removal of the catheter (Agency for Health Care Research and Quality, 2016).

\section{Significance of the study}

Central venous access is a commonly performed procedure in PICU with approximately $8 \%$ of hospitalized patients requiring central venous access during the course of their hospital stay (Ruesch, et al., 2018).

Limited research has been conducted on auditing of CVC insertion, so the information obtained from this research helps the pediatric nurses and other health professionals to gain practice regarding the nursing care of central venous access care.

\section{Aim of the Study}

The study aimed at auditing and re-auditing nursing care for children undergoing central venous line insertion in Pediatric Intensive Care Unit.

\section{Research hypotheses}

- The nurses may have unsatisfactory practice regarding central venous care during auditing.

- The nurse's practice regarding central venous care improves after re- auditing.

\section{Operational definition}

Nursing auditing is defined as using a framework of nursing functions to specify in considerable details what the criteria should be used. However, it is left to the reviewers to judge the extent to which nursing care has measured up to professional standards in each of the characteristics that are specified. There are two methods for auditing. The first method is the retrospective view which refers to an in-depth assessment of quality after the patient has been discharged, and uses the patients' chart as the source of data. The second method is a concurrent view which refers to the evaluations conducted on behalf of patients who are still undergoing care (Coyne et al., 2016).

\section{Subjects \& Method Study design}

A quasi-experimental research design was used in this study.

\section{Setting of the study}

This study was conducted in Pediatric Intensive Care Unit at Assiut University Children Hospital.

\section{Subjects}

Convenience sample was obtained from nurses who working at the previously mentioned setting. They were 33 nurses, fifteen of them graduated from the Secondary School of Nursing, eleven graduated from the Technical Institute of Nursing and seven had a Bachelor's Degree in Nursing.

\section{Tools of data collection}

Two tools were utilized to collect data pertinent to the study

Tool one: A structured interview questionnaire sheet for nurses. It consists of two parts.

Part (1): Biosocial characteristics of the nurses such as age, qualification, years of experience, residence, and training courses received.

Part (2): Data related to the procedure

This part included data such as procedure date, procedure time, insertion site, catheter type and type of procedure.

Tool two: Indirect observational checklist adopted from (CDC, 2011) to audit the nurse's practice related to central venous line care which includes:

Part (a): Central Venous Line Insertion Care monitoring sheet:

This part included a structured indirect observational checklist to audit the nurse's practice related to central venous line insertion care which included:

- (11 items/ questions) before the procedure,

- (14 items/ questions) during the procedure,

- (5 items/ questions) after the procedure.

Part (b): Central Venous Line Dressing and routine care monitoring sheet:

This part included a structured indirect observation checklist to audit the nurse's practice related to central venous line dressing and routine care which included

- Dressing change

(21 items),

- Heparinization

(11items),

- Medication administration (14 items).

Scoring system: The items observed to be done completely were scored "2", the items observed to be done incompletely were scored "1"and the items not done were scored "0". The practice was considered satisfactory if it was $(70 \%$ or more) and unsatisfactory if it was $(<70 \%)$ (Peduzzi et al., 2006).

\section{Data collection}

- An official permission was obtained from the director of the Pediatric Intensive Care Unit at Assiut University Children Hospital to collect the necessary data after clarifying the nature of the study.

\section{Pilot study}

A pilot study was conducted on three of the nurses (10\%) working in Pediatric Intensive care unit at Assiut University Children Hospital. The pilot study was conducted to test clarity and completeness, and to determine the time involvement. According to the 
results of the pilot study no modification, omissions, and/or additions were made. The nurses in the pilot study were included in the total sample.

\section{Validity}

The validity of tool two was estimated by 5 experts in the pediatric and pediatric nursing field and its result was $97 \%$

\section{Reliability}

Reliability was estimated by Alpha Cronbach's test for tool two and its result was $\mathrm{R}=0.83$

\section{Ethical consideration}

Ethical approval was obtained from the Ethical Committee at the Faculty of Nursing, Assiut University. The purpose of the study was explained to the participants by the researcher through direct personal communication prior to starting their participation in the study. Also the nurses were informed that they had the right to agree or disagree to participate in the study. The written consent was taken from all nurses participating in the study and they were informed that data was confidential between them and the researcher and would be used for the purpose of the research only.

\section{Field of the work}

The field of work was carried out through a period of five months from August 2018 to December 2018.

The actual work started by meeting the nurses during the official working hours throughout different daily shifts, then the researcher first introduced herself to the nurses and gave them background information about the study. After that the auditing was done through an indirect observational checklist for all nurses. The researcher interviewed 1-2 nurses throughout different nursing shifts such as morning and afternoon shift two days weekly. Every nurse received three sessions. The duration of each session was variable, and ranged between 60 and 90 minutes. In the first session the auditing was done, and in the second session the teaching guidelines were implemented for nurses in the form of brochures. Each participant obtained a copy of the brochures that included all the training material. Finally, after three months of giving the teaching guidelines, reauditing was done.

\section{Analysis of data}

Data entry was done using Epi-Info 6.04 computer software package, while statistical analysis was done using (SPSS) version 20 statistical software package. Data were presented using descriptive statistics in the form of frequencies and percentages for qualitative variables, and means and standard deviations for quantitative variables. Statistical significance was considered at $\mathrm{p}$-value $<0.05$.

\section{Results}

Table (1): Distribution of pediatric nurses according to their personal data $(n=33)$

\begin{tabular}{|c|c|c|}
\hline Characteristics & No. & $\%$ \\
\hline \multicolumn{3}{|l|}{ Nurses' Age/years } \\
\hline \multirow{3}{*}{$\begin{array}{ll} & 20<30 \\
\bullet & 30-40 \\
\bullet & \text { Mean } \pm \text { SD }\end{array}$} & 28 & 84.8 \\
\hline & 5 & 15.2 \\
\hline & $26.6 \pm 4.8$ & \\
\hline \multicolumn{3}{|l|}{ Qualifications } \\
\hline \multirow{3}{*}{ 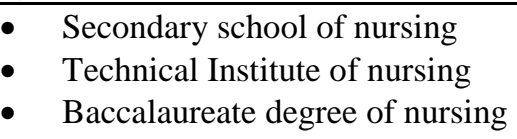 } & 15 & 45.5 \\
\hline & 11 & 33.3 \\
\hline & 7 & 21.2 \\
\hline \multicolumn{3}{|l|}{ Years of experience } \\
\hline$\bullet<5$ & 24 & 72.7 \\
\hline - $5-10$ & 4 & 12.1 \\
\hline - $>10$ & 5 & 15.2 \\
\hline$\bullet \quad$ Mean \pm SD & $1.4 \pm 0.75$ & \\
\hline \multicolumn{3}{|l|}{ Residence } \\
\hline$\bullet \quad$ Rural & 20 & 60.6 \\
\hline$\bullet \quad$ Urban & 13 & 39.4 \\
\hline \multicolumn{3}{|l|}{ Previous training about CVC } \\
\hline$\bullet \quad$ Yes & 0 & 0.00 \\
\hline - $\quad$ No & 33 & 100 \\
\hline
\end{tabular}


Table (2): Distribution of nurses concerning their practice before CVC insertion in the auditing and reauditing $(n=33)$.

\begin{tabular}{|c|c|c|c|c|c|}
\hline \multirow{2}{*}{ Items } & \multicolumn{2}{|c|}{ Auditing } & \multicolumn{2}{|c|}{ Re-auditing } & \multirow{2}{*}{ p. value } \\
\hline & $\mathbf{N}$ & $\%$ & $\mathbf{N}$ & $\%$ & \\
\hline - $\quad$ The nurses wash their hands. & 4 & 12.1 & 18 & 54.5 & $0.054 *$ \\
\hline - $\quad$ The nurses wear gloves. & 12 & 36.4 & 24 & 72.7 & $0.015^{*}$ \\
\hline $\begin{array}{l}\text { - The CVC insertion procedure is performed in a } \\
\text { sterile place (procedure room/operating room. }\end{array}$ & 1 & 3.0 & 18 & 54.5 & $0.003 *$ \\
\hline $\begin{array}{l}\text { The required equipments and supplies of the } \\
\text { procedure are prepared. }\end{array}$ & 3 & 9.1 & 18 & 54.5 & 0.082 \\
\hline $\begin{array}{l}\text { - The appropriate site of inserting CVC is chosen } \\
\text { correctly according to the patient's condition. }\end{array}$ & 1 & 3.0 & 18 & 54.5 & $0.003 *$ \\
\hline - The procedure is explained to the patient. & 1 & 3.0 & 4 & 12.1 & 0.982 \\
\hline - A large drape is used to cover the patient. & 1 & 3.0 & 16 & 48.5 & $0.005 *$ \\
\hline - $\quad$ The patient wears mask and overhead. & 2 & 6.1 & 7 & 21.2 & 0.324 \\
\hline $\begin{array}{l}\text { The nurse puts the patient in a suitable, } \\
\text { comfortable position according to the procedure site. }\end{array}$ & 0 & 0.0 & 16 & 48.5 & $0.010^{*}$ \\
\hline $\begin{array}{l}\text { The place of CVC insertion was cleaned by a } \\
\text { sterile normal saline. }\end{array}$ & 2 & 6.1 & 16 & 48.5 & 0.070 \\
\hline $\begin{array}{l}\text { The place of CVC insertion was disinfected by } 2 \% \\
\text { cholrhexidine then left } 2-5 \text { minutes until drying. }\end{array}$ & 1 & 3.0 & 18 & 54.5 & $0.003 *$ \\
\hline
\end{tabular}

N.B: $p$ value is significant if ${ }^{*} P<0.05$

Table (3): Distribution of nurses concerning their practice during CVC insertion in the auditing and reauditing $(n=33)$.

\begin{tabular}{|c|c|c|c|c|c|}
\hline \multirow{2}{*}{ Items } & \multicolumn{2}{|c|}{ Auditing } & \multicolumn{2}{|c|}{ Re- auditing } & \multirow{2}{*}{ P. value } \\
\hline & $\mathbf{N}$ & $\%$ & $\mathbf{N}$ & $\%$ & \\
\hline - The surgical hand washing is done by physician and nurse. & 4 & 12.1 & 18 & 54.5 & $0.054 *$ \\
\hline - $\quad$ The physician and the nurse use gloves. & 14 & 42.4 & 18 & 54.5 & 0.956 \\
\hline - $\quad$ The physician and the nurse use a gown. & 1 & 3.0 & 11 & 33.3 & $0.023 *$ \\
\hline - $\quad$ The physician and the nurse use mask. & 1 & 3.0 & 5 & 15.2 & 0.123 \\
\hline - $\quad$ The physician and the nurse use overhead. & 1 & 3.0 & 3 & 9.1 & 0.90 \\
\hline $\begin{array}{l}\text { - The procedure of CVC insertion was performed by } \\
\text { maintaining a sterile field. }\end{array}$ & 1 & 3.0 & 12 & 36.4 & $0.052 *$ \\
\hline $\begin{array}{l}\text { - The nurse assists during performing ultrasound throughout } \\
\text { the procedure. }\end{array}$ & 1 & 3.0 & 2 & 6.1 & 0.958 \\
\hline $\begin{array}{l}\text { - The nurse makes sure that all ports of the catheter are not } \\
\text { open during insertion to avoid air embolism. }\end{array}$ & 1 & 3.0 & 18 & 54.5 & $0.003 *$ \\
\hline $\begin{array}{l}\text { - The nurse monitors the patient's heart rate, rhythm, and } \\
\text { response throughout the procedure. }\end{array}$ & 10 & 30.3 & 18 & 54.5 & 0.903 \\
\hline $\begin{array}{l}\text { The nurse aspirates blood from each port of the catheter then } \\
\text { flushes the ports with saline or sterile water. }\end{array}$ & 1 & 3.0 & 18 & 54.5 & $0.003 *$ \\
\hline $\begin{array}{l}\text { The nurse makes sure that the number of wires used during } \\
\text { CVC insertion is the same before and after CVC insertion } \\
\text { procedure. }\end{array}$ & 4 & 12.1 & 18 & 54.5 & $0.054 *$ \\
\hline - $\quad$ The nurse assists during securing the catheter with suture. & 2 & 6.1 & 18 & 54.5 & $0.019 *$ \\
\hline $\begin{array}{l}\text { - The nurse does not administrate any fluids or medications } \\
\text { via the line until verification of placement is done unless in an } \\
\text { emergency situation. }\end{array}$ & 1 & 3.0 & 16 & 48.5 & $0.005^{*}$ \\
\hline - A sterile dressing is applied after insertion of CVC. & 7 & 21.2 & 16 & 48.5 & 0.717 \\
\hline
\end{tabular}

N.B: $p$ value is significant if ${ }^{*} P<0.05$

Vol , (7) No , (17) June, 2019 
Table (4): Distribution of nurses concerning their practice after CVC insertion in the auditing and reauditing $(n=33)$.

\begin{tabular}{|c|c|c|c|c|c|}
\hline \multirow{2}{*}{ Items } & \multicolumn{2}{|c|}{ Auditing } & \multicolumn{2}{|c|}{ Re- auditing } & \multirow{2}{*}{ P. value } \\
\hline & $\mathbf{N}$ & $\%$ & $\mathbf{N}$ & $\%$ & \\
\hline $\begin{array}{l}\text { - An x-ray of the catheter tip was done to verify catheter } \\
\text { placement. }\end{array}$ & 2 & 6.1 & 16 & 48.5 & $0.001 * *$ \\
\hline $\begin{array}{l}\text { - The nurse connects new administration sets and fluids to } \\
\text { the catheter port after verification of placement of CVC and } \\
\text { never connects previously used IV tubing to the new central } \\
\text { venous access the line. }\end{array}$ & 2 & 6.1 & 14 & 42.4 & $0.013 *$ \\
\hline $\begin{array}{l}\text { - The maximal sterile barrier precautions (gloves, gown, } \\
\text { mask, and overhead) were removed and disposed. }\end{array}$ & 5 & 15.2 & 18 & 54.5 & $0.025^{*}$ \\
\hline $\begin{array}{l}\text { - There is a proper disposal of the equipment and supplies } \\
\text { (sharp needle). }\end{array}$ & 4 & 12.1 & 18 & 54.5 & $0.054 *$ \\
\hline - The nurse records and documents the procedure. & 6 & 18.2 & 10 & 30.0 & 0.932 \\
\hline
\end{tabular}

N.B: $p$. value is significant if ${ }^{*} P<0.05$

Table (5): Distribution of nurses' practice related to dressing changes of $\mathrm{CVC}$ in the auditing and re-auditing. $(\mathbf{n}=33)$.

\begin{tabular}{|c|c|c|c|c|c|}
\hline \multirow{2}{*}{ Items } & \multicolumn{2}{|c|}{ Auditing } & \multicolumn{2}{|c|}{ Re-auditing } & \multirow{2}{*}{ P. value } \\
\hline & $\mathbf{N}$ & $\%$ & $\mathbf{N}$ & $\%$ & \\
\hline - $\quad$ The nurse washed her hand before dressing. & 10 & 30.3 & 17 & 51.5 & 0.292 \\
\hline $\begin{array}{l}\text { The nurse prepares the equipment for changing the dressing } \\
\text { of CVC. }\end{array}$ & 2 & 6.1 & 17 & 51.5 & $0.003^{*}$ \\
\hline - $\quad$ The nurse explains the procedure to the child. & 2 & 6.1 & 11 & 33.3 & $0.013^{*}$ \\
\hline - The nurse maintains the patient's privacy. & 1 & 3.0 & 13 & 39.4 & $0.012 *$ \\
\hline $\begin{array}{l}\text { The nurse puts the child at a suitable position for the } \\
\text { procedure. }\end{array}$ & 2 & 6.1 & 17 & 51.5 & $0.003 *$ \\
\hline $\begin{array}{l}\text { The nurse washes her hand with alcohol, betadine } 7.5 \% \text { or } \\
\text { chlorohexidine before the procedure. }\end{array}$ & 3 & 9.1 & 18 & 54.5 & $0.014 *$ \\
\hline - $\quad$ The nurse wears a mask and sterile gloves. & 0 & 0.0 & 5 & 15.2 & $0.051^{*}$ \\
\hline - $\quad$ The child wears a mask. & 1 & 3.0 & 9 & 27.3 & $0.03 *$ \\
\hline $\begin{array}{l}\text { The nurse observes the catheter site for redness, erythema, } \\
\text { any signs of infection (tenderness, warmth, odema). }\end{array}$ & 1 & 3.0 & 18 & 54.5 & $0.003 *$ \\
\hline - $\quad$ The dressing of CVC was changed after 48 hours. & 1 & 3.0 & 18 & 54.5 & $0.003 *$ \\
\hline $\begin{array}{l}\text { The dressing of CVC is changed when it is infected or } \\
\text { becomes wet. }\end{array}$ & 12 & 36.4 & 18 & 54.5 & 0.143 \\
\hline $\begin{array}{l}\text { The nurse fixes the catheter well during care and dressing } \\
\text { application. }\end{array}$ & 10 & 30.3 & 18 & 54.5 & 0.903 \\
\hline $\begin{array}{l}\text { The nurse cleans the skin surrounding CVC in the right way } \\
\text { by using alcohol (in a circular motion from the inside to the } \\
\text { outside or in a hesitated line without coming back to the starting } \\
\text { point ( } 10 \mathrm{~cm} \text { diameter). }\end{array}$ & 1 & 3.0 & 18 & 54.5 & $0.003 *$ \\
\hline The nurse repeats the last step twice. & 1 & 3.0 & 5 & 15.2 & 0.305 \\
\hline $\begin{array}{l}\text { - The nurse disinfects the surrounding of CVC in the same } \\
\text { way of cleaning using chlorohexidine } 10 \% \text {. }\end{array}$ & 1 & 3.0 & 18 & 54.5 & $0.003 *$ \\
\hline $\begin{array}{l}\text { - The nurse disinfects the section of the catheter that lies } \\
\text { adjacent to the skin. }\end{array}$ & 1 & 3.0 & 5 & 15.2 & 0.305 \\
\hline $\begin{array}{l}\text { The nurse disinfects the connection between each CVC hub } \\
\text { and caps to the bifurcation of central line. }\end{array}$ & 1 & 3.0 & 3 & 9.1 & 0.90 \\
\hline $\begin{array}{l}\text { - The nurse lets disinfection solution } 1 \text { minute until dry on the } \\
\text { catheter site. }\end{array}$ & 1 & 3.0 & 13 & 39.4 & $0.012 *$ \\
\hline $\begin{array}{l}\text { If the CVC will be removed, the nurse disinfects the site of } \\
\text { catheter removal about } 10 \text { minutes around using alcohol. }\end{array}$ & 1 & 3.0 & 14 & 42.4 & $0.025^{*}$ \\
\hline - $\quad$ The nurse applies sterile dressing after disinfection. & 8 & 24.2 & 18 & 54.5 & $0.021 *$ \\
\hline - $\quad$ The nurse removed the gloves and washed hands. & 5 & 15.2 & 18 & 54.5 & $0.025^{*}$ \\
\hline
\end{tabular}

N.B: $p$ value is significant if ${ }^{*} P<0.05$

Vol , (7) No , (17) June, 2019 
Table (6): Distribution of nurses' practice related to heparinization of CVC in the auditing and re-auditing. $(\mathbf{n}=33)$.

\begin{tabular}{|l|c|c|c|c|c|c|}
\hline \multirow{2}{*}{ Items } & \multicolumn{2}{|c|}{ Auditing } & \multicolumn{3}{|c|}{ Re- auditing } & \multirow{2}{*}{ P. value } \\
\cline { 2 - 6 } & $\mathbf{N}$ & $\mathbf{\%}$ & $\mathbf{N}$ & \% & \\
\hline - The nurse washes her hand. & 6 & 18.2 & 18 & 54.5 & 0.36 \\
\hline - The nurse wears gloves. & 13 & 39.4 & 18 & 54.5 & 0.488 \\
\hline The nurse prepares the needed equipment. & 3 & 9.1 & 16 & 48.5 & $0.012^{*}$ \\
\hline $\begin{array}{l}\text { The nurse scrubs the hub for at least 15 } \\
\text { seconds using a 2\% chlorhexidine and 70\% } \\
\text { isopropyl alcohol impregnanted wipe before } \\
\text { injecting heparin. }\end{array}$ & 1 & 3.0 & 18 & 54.5 & $0.003^{*}$ \\
\hline $\begin{array}{l}\text { - The nurse injects CVC with diluted heparin } \\
\text { using 10 cm syringe daily. }\end{array}$ & 8 & 24.2 & 18 & 54.5 & $0.025^{*}$ \\
\hline $\begin{array}{l}\text { - The pumping of heparin is done in a right way } \\
\text { (slowly). }\end{array}$ & 1 & 3.0 & 18 & 54.5 & $0.003^{*}$ \\
\hline $\begin{array}{l}\text { - The nurse disinfects all parts of the catheter } \\
\text { before injecting any fluids. }\end{array}$ & 0 & 0.0 & 10 & 30.3 & $0.005^{*}$ \\
\hline $\begin{array}{l}\text { - The nurse changes the catheter caps at least } \\
\text { once weekly. }\end{array}$ & 1 & 3.0 & 13 & 39.4 & $0.013^{*}$ \\
\hline - The nurse discards the syringe correctly. & 9 & 27.3 & 18 & 54.5 & 0.871 \\
\hline The nurse washes her hands. & 12 & 36.4 & 15 & 45.5 & 0.95 \\
\hline $\begin{array}{l}\text { The nurse records and reports all the } \\
\text { observations in the patient's sheet. }\end{array}$ & 0 & 0.0 & 8 & 24.2 & $0.05^{*}$ \\
\hline
\end{tabular}

N.B: $p$ value is significant if ${ }^{*} P<0.05$

Table (7): Distribution of nurses' practice related to medication administration through $\mathrm{CVC}$ in the auditing and re-auditing $(\mathrm{n}=33)$.

\begin{tabular}{|c|c|c|c|c|c|}
\hline \multirow[b]{2}{*}{ Items } & \multicolumn{2}{|c|}{ Auditing } & \multicolumn{2}{|c|}{ Re- auditing } & \multirow[t]{2}{*}{ P. value } \\
\hline & $\mathbf{N}$ & $\%$ & $\mathbf{N}$ & $\%$ & \\
\hline - $\quad$ The nurse washes hand. & 13 & 39.4 & 33 & 100.0 & $0.017 *$ \\
\hline - $\quad$ The nurse wears gloves. & 18 & 54.5 & 33 & 100.0 & $0.025^{*}$ \\
\hline - $\quad$ The nurse prepares the needed equipment in a sterile tray. & 1 & 3.0 & 29 & 87.9 & $0.0001 *$ \\
\hline $\begin{array}{l}\text { - The nurse scrubs the hub for at least } 15 \text { seconds using a } 2 \% \\
\text { chlorhexidine and } 70 \% \text { isopropyl alcohol impregnated wipe before } \\
\text { injecting medication. }\end{array}$ & 2 & 6.1 & 19 & 57.6 & $0.015^{*}$ \\
\hline $\begin{array}{l}\text { - The nurse prepares medication as prescribed or uses pharmacy } \\
\text { prepared medication. }\end{array}$ & 32 & 97.0 & 33 & 100.0 & 0.975 \\
\hline $\begin{array}{l}\text { - The nurse uses sterile gloves if she must touch (needle, syringe, } \\
\text { CVC line connection, exposed vascular catheter lumen). }\end{array}$ & 0 & 0.0 & 17 & 51.5 & $0.018 *$ \\
\hline $\begin{array}{l}\text { - The nurse disinfects all parts of the catheter before injecting any } \\
\text { fluids. }\end{array}$ & 1 & 3.0 & 20 & 60.6 & $0.016 *$ \\
\hline $\begin{array}{l}\text { - The nurse allows disinfected parts of the catheter to dry for } 15 \\
\text { seconds before injecting any fluids. }\end{array}$ & 0 & 0.0 & 22 & 66.7 & $0.015 *$ \\
\hline $\begin{array}{l}\text { - The nurse administers medication using an aseptic non-touch } \\
\text { technique. }\end{array}$ & 1 & 3.0 & 25 & 75.8 & $0.012 *$ \\
\hline - $\quad$ The nurse doesn't recap the syringe to avoid needle stick injury. & 4 & 12.1 & 30 & 90.9 & $0.014 *$ \\
\hline $\begin{array}{l}\text { - The nurse discards the syringe and the equipment according to } \\
\text { its content correctly. }\end{array}$ & 11 & 33.3 & 32 & 97.0 & $0.019 *$ \\
\hline - $\quad$ The nurse washes her hands. & 15 & 45.5 & 32 & 97.0 & $0.025 *$ \\
\hline $\begin{array}{l}\text { - The nurse records and reports all the observations in the patient's } \\
\text { sheet. }\end{array}$ & 1 & 3.0 & 20 & 60.06 & $0.016 *$ \\
\hline - The nurse changes the catheter caps at least once weekly. & 1 & 3.0 & 28 & 84.8 & $0.011 *$ \\
\hline
\end{tabular}

N.B: P. value is significant if ${ }^{*} P<0.05$ 


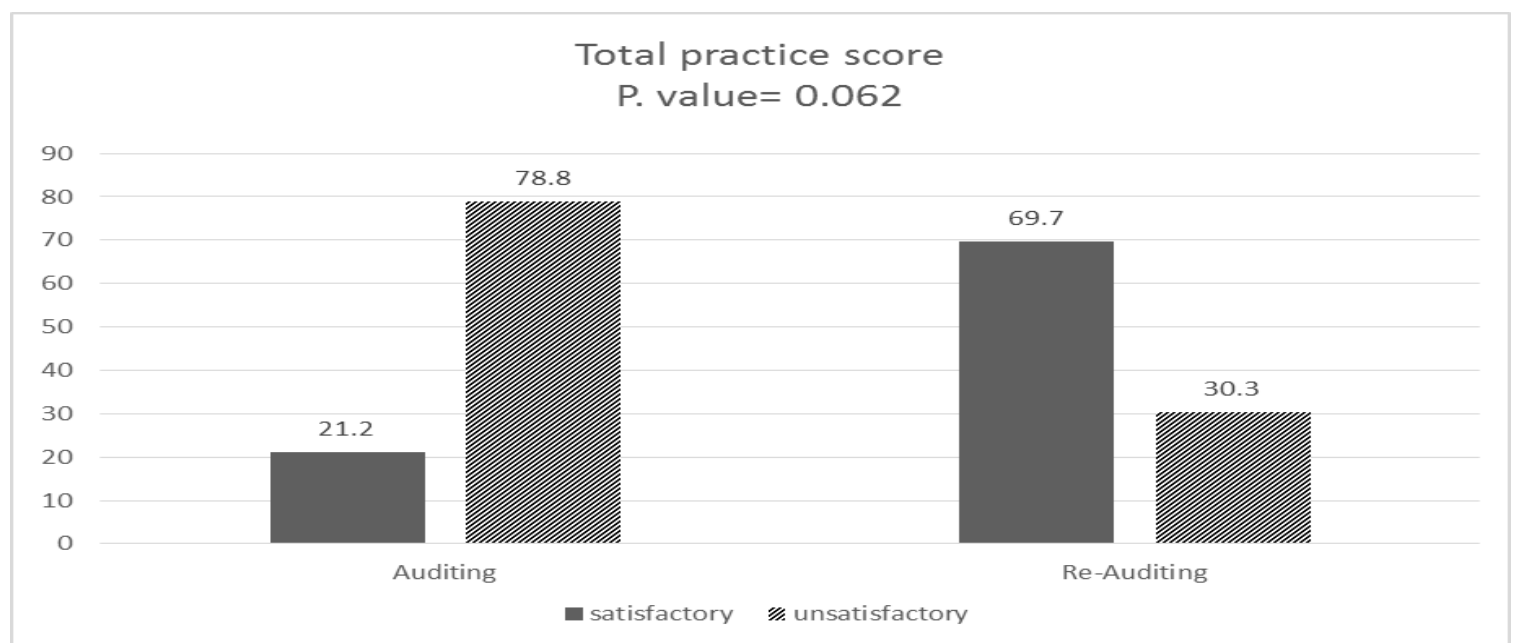

Figure (1): Distribution of nurses' total practice score related to CVC care in the auditing and re-auditing.

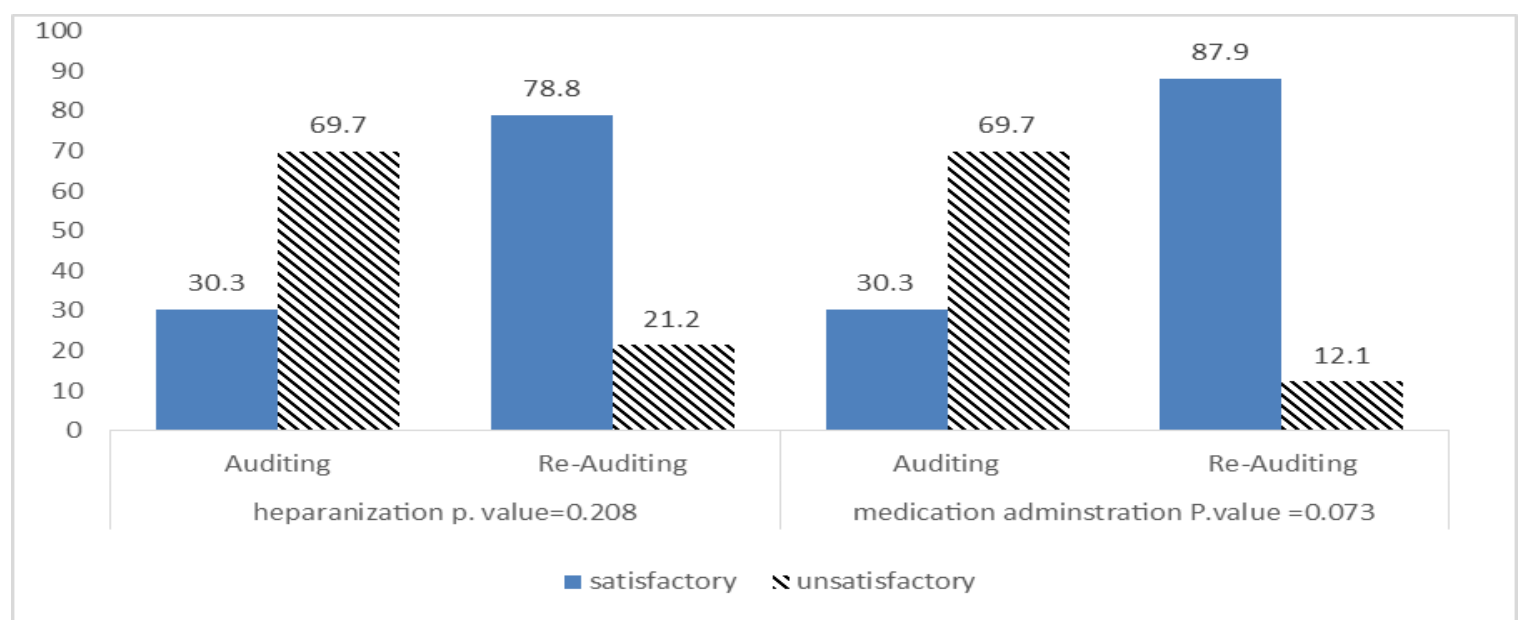

Figure (2): Distribution of nurses regarding the total score of their practice related to CVC heparanization and medication administration in the auditing and re- auditing.

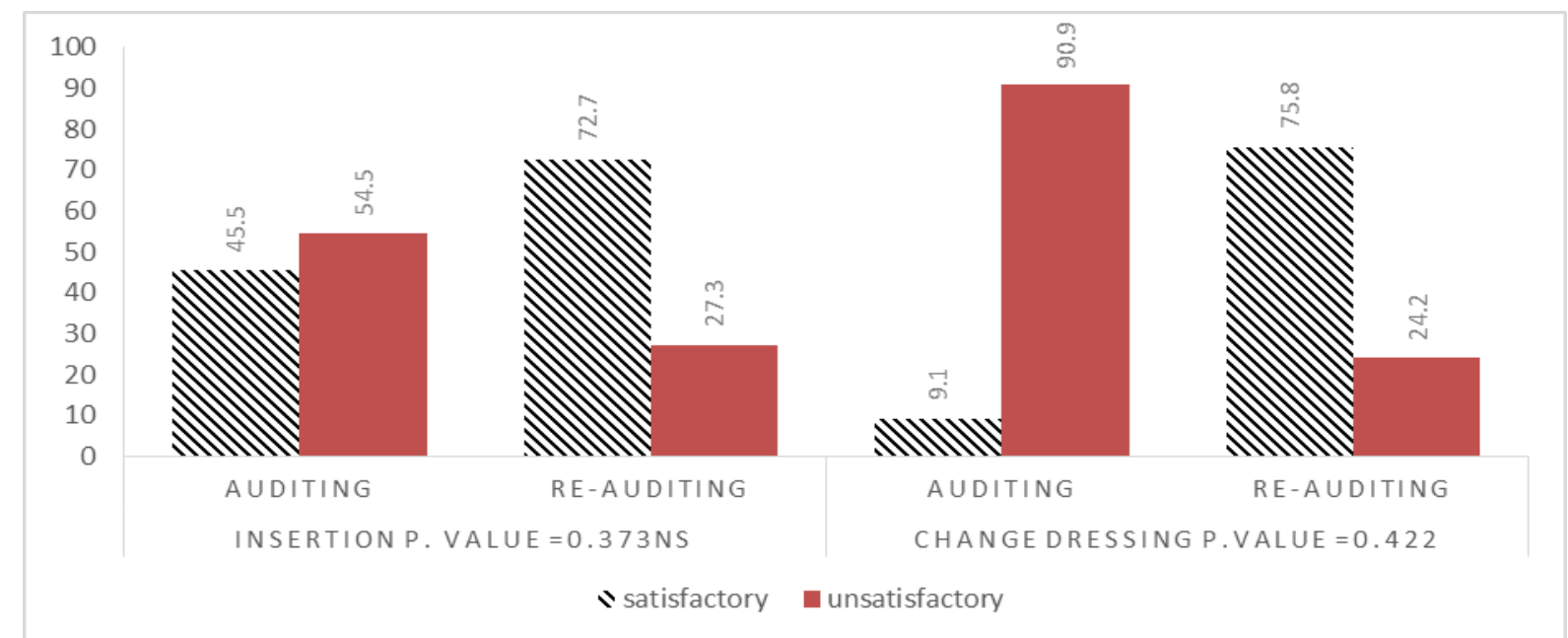

Figure (3): Distribution of nurses regarding their total score of practice about CVC insertion and dressing change in the auditing and re- auditing. 
Table (1): Shows the distribution of pediatric nurses according to their personal data.

It was found that $84.8 \%$ of the nurses were aged $20<$ 30 years and $45.5 \%$ graduated from the secondary school of nursing. As regards years of experience it was noticed that $72.7 \%$ of them had less than five years. Furthermore, $60.6 \%$ of them resided in the rural areas. Finally, the results indicated that all nurses didn't receive any previous training in CVC.

Table (2): Shows the distribution of nurses concerning their practice before $\mathrm{CVC}$ insertion in the auditing and re-auditing. The results indicated that statistically significant differences were detected between the nurses' practice in the auditing and reauditing related to seven steps (i.e., washing hands, wearing gloves, performing procedure in a sterile place, choosing the appropriate site of insertion, using a large drape to cover the patient, putting the patient in a suitable position and disinfecting the place of insertion $(\mathrm{p}=0.054,0.015,0.003,0.003$, $0.005,0.010$ and 0.003 , respectively), while no statistically significant differences were detected between as regards the other steps.

Table (3): Illustrates the distribution of nurses concerning their practice during insertion of CVC. It was clear from this table that statistically significant differences were detected as regards nurses' practice in the auditing and re-auditing for all steps $(\mathrm{p}=0.054$, $0.023,0.052,0.003,0.003,0.054,0.019$ and 0.005 ), while no statistically significant differences were found for using the gloves, mask and overhead by the physician and the nurse, the nurse assisting during performing ultrasound throughout the procedure and applying a sterile dressing after insertion of CVC.

Table (4): Shows the distribution of nurses regarding their practice after insertion of CVC in the auditing and re-auditing. Statistically significant differences were detected as regards the nursing practice in the auditing and re- auditing for all steps $\mathrm{P}=(0.001$, $0.013,0.025$ and 0.054$)$, except for recording and documenting the procedure.

Table (5): Illustrates the distribution of nurses' practice related to dressing change of CVC in the auditing and re-auditing. It was found that a statistically significant differences were detected between the majority of procedure items except for hand washing, changed the CVC dressing when infected ,fixed the catheter during the care, repeated the cleaning of the skin surround CVC, disinfected the section of the catheter adjacent to the skin and disinfected the connection between each CVC hub and caps that show no statistically significant differences were detected in between $\mathrm{p}=(0.292,0.143$, $0.903,0.305,0.305 \%$ and $0.90 \%$ respectively).
Table (6): Indicates the distribution of nurses' practice related to heparanization of $\mathrm{CVC}$ in the auditing and re- auditing. The results revealed that only $(9.1 \%)$ of the studied nurses prepared the equipments needed for heparanization in the auditing compared with $48.5 \%$ in the re-auditing. Also only $3.0 \%$ of the studied nurses scrubbed the hub with an anti-septic solution before injecting the heparin, pumped the heparin in a right way and changed the catheter caps at least once weekly in the auditing, which increased to $54.5 \%, 54.5 \%$, and $39.4 \%$, respectively in the re-auditing. Moreover, the results indicated that all studied nurses completely neglected disinfecting all parts of the catheter before injecting any fluids, recording and reporting all the observation in the patient's sheet in the auditing while $30.3 \%$ and $24.2 \%$ of them respectively did these steps it in the re- auditing. Statistically significant differences were detected $(\mathrm{p}=0.012,0.003,0.003,0.013,0.005$ and 0.05 , respectively).

Table (7): Reveals the distribution of nurses' practice related to medication administration through CVC in the auditing and re-auditing. The present study found that statistically significant differences were detected as regards all items except for preparing medication as prescribed.

Figure (1): Reveals the distribution of the total score of the nurses' practice related to CVC care in the auditing and re-auditing. It was clear from this figure that more than three-quarters of the nurses $(78.8 \%)$ had unsatisfactory practice in the auditing, which declined to $30.3 \%$ in the re-auditing.

Figure (2): Indicates the distribution of nurses regards the total score of practice related to CVC heparanization and medication administration in the auditing and re-auditing. Concerning the heparanization, the present study illustrated that more than two-thirds of the nurses $(69.7 \%)$ had unsatisfactory practice in the auditing, which decreased to $21.2 \%$ in the re-auditing. Moreover, the results indicated that more than two-thirds of the nurses $(69.7 \%)$ had unsatisfactory practice as regards medication administration in the auditing, which decreased to $12.1 \%$ in re-auditing.

Figure (3): Shows the distribution of nurses regarding their total score of practice regarding CVC insertion and dressing change in the auditing and reauditing.

Concerning CVC insertion, the study revealed that more than half of the nurses (54.5\%) had unsatisfactory practice in the auditing, which decreased to $27.3 \%$ in the re-auditing. As for the dressing change, it was noticed that the majority of them $(90.9 \%)$ had unsatisfactory practice in the auditing, which declined to $24.2 \%$ in the re-auditing. 


\section{Discussion}

The purpose of nursing auditing is to evaluate the nursing care given to achieve the desired and viable quality of nursing care (Vanstaa et al., (2015).

Each organization and profession must set standards and objectives to guide individuals and practitioners in performing safe and effective care. Also standards not only must exist, but also leaders and managers must see that subordinates know and understand the standards and employees must be aware that their practice will be measured in terms of their ability to meet the established standards Marquis\& Huston, (2009).

Statistically significance differences were detected between the nurses' practice in the auditing and reauditing related to the majority of item in table 2 before CVC insertion. These results are consistent with Babu et al. (2016) who showed that washing hands, wearing gloves, using aseptic technique, using a sterile room, selecting an appropriate catheter site and covering the patient with a large drape are very important steps which must be taken into consideration before inserting the CVC. Also the child must be put in a suitable and comfortable position during the procedure to ease the insertion.

The results showed that a low percentage of the nurses used the universal precautions during CVC insertion such as performing the surgical hand washing, using a gown and maintaining a sterile field as in the auditing. The results reached by Hill, (2018) demonstrated that during insertion of $\mathrm{CVC}$, the surgical hand washing must be done by the physician and nurse, and the procedure of CVC insertion should be performed by maintaining a sterile field. As in the usual preparation described for any aseptic surgical procedure, the nurse should scrub the hands with an antimicrobial soap, dry with a sterile towel, and wear gloves to remove any microorganisms that are on the surface of the skin.

In addition, a low percentage of the nurses should make sure that all ports of the catheter are closed during insertion, aspirate blood from each port of the catheter, then flush with saline or sterile water, make sure that the number of wires is the same before and after insertion, and that the catheter is secured with suture and the nurse doesn't administer any fluids or medications via the line until verification of placement was done. This is in the same line with $\mathbf{A l}$ kubati et al., (2015) who found that the overall level of nurses' agreement with the recommended evidence based practice (EBP) during CVC insertion was less than a half, which is considered low.

The present study indicated that a low percentage of the nurses in the auditing did the x-ray, used the universal precautions during removal and disposal of disposable materials and sharp equipment, and recorded and documented the procedure. Woodland et al., (2018) emphasized that routine post-insertion $\mathrm{X}$-rays have become a standard of care and contribute to health care costs with a limited impact on patient management. Also Al Salmi \& Kadium., (2013) assured that after CVC insertion, the masks, gloves and overhead should be removed and disposed, equipment and supplies (sharp needle) should be disposed of properly, and the nurse must record and document the procedure.

The findings revealed that the majority of nurses' practice scores was inadequate as regards preparing equipment, explaining procedure, observing the catheter site for signs of infection, the sterile barrier precautions, scrub the hub, pumping the heparin in a right way, recording and reporting all the observations in the patient's sheet. The current study results are in agreement with the findings of the study conducted by Gahlot et al., (2014) Also the results are in the same line with Abdelsatir (2013) who found that guideline recommendations for routine preventive care are not always followed, so continuous education is very important. The findings of the present study disagree with those reported by Rosenthal et al., (2010) who studied nurses during care of CVC in ICUs in 15 developing countries and found that less than half of them used maximal sterile barrier precautions during the insertion of CVCs.

The low percentages of nurses' adherence to maximal sterile barrier precautions in the present study could be attributed to several reasons, including inadequate knowledge about the importance of maximal sterile barrier precautions for nurses during CVC insertion and prevention of infection. Moreover, the healthcare workers' knowledge about infection prevention guidelines was generally low.

Concerning the total score of the nurse's practice related to $\mathrm{CVC}$ care, it was observed that more than three-quarters of the nurses had unsatisfactory practice in the auditing. This can be accounted for by the fact that all the studied nurses didn't attend any training courses in CVC insertion and care.

Finally the study showed that a high percentage of the nurses had unsatisfactory practice in auditing with enhancement in their practice in re-auditing, regarding CVC insertion, dressing change, CVC heparanization and medication administration. This is consistent with Cooper, (2019). From the researcher' point of view, the findings of the present study may be attributed to several factors, including lack of adequate hand washing facilities, supplement of masks, gloves, caps, and gowns during CVC insertions, and maintenance care. Moreover, they may also be attributed to nursing staff shortage, nursing work overload, the time constraints of having to connect or disconnect a large number of patients 
within a limited time, and lack of knowledge and awareness as a result of a lack of training programs, as our findings illustrated.

\section{Conclusion}

Based on the results of the present study, reauditing of nurses caring for children undergoing central venous line insertion improved significantly than auditing.

\section{Recommendations}

In the light of the study findings, the following recommendations are suggested.

- Pediatric nurses should update their knowledge and practice through continued nursing education, training, and frequently attending seminars and conferences especially in infection control skills.

- Educational guidelines, posters, pamphlets and manuals about central venous line should be provided and made available at each nursing station in the intensive care unit.

- Availability of equipment and disinfectants needed in PICU for applying a sterile field.

\section{References}

1. Abdelsatir S., (2013): Evaluation of nurse's awareness and practice of hemodialysis access care in Khartoum State. Sudan Arab J Nephrol Transplant (6):119-121.

2. American society of anesthesiologist, (2012): practice guideline for central venous access, 116(3):539-73.

3. Agency for Health Care Research and Quality, (2016): central line associated blood stream infections 22-31 available from: http://www.ahrq.gov/professionals/education/cu rriculm/tools/clabsitools/clabsitoolsap2.html.rev ised at Novmber7.

4. Ahmad B., khan M., \& Beg A., (2016): Frequency of central venous catheter related infections and their culture and sensitive pattern. Journal of Islamabad medical and dental college 5(2): 63-66.

5. Al Kubati S., Ahmed N., Mohamed O., Fayed A., \& Asfour A., (2015): Health care workers' knowledge and practices regarding the prevention of central venous catheter-related infection. Am J Infect Control 43: 26-30.

6. Al Salmi S., \& Kadium M., (2013): An education intervention to improve nurses' knowledge to reduce catheter-related bloodstream infection in Hemodialysis Unit Walden University. Int J Sci Res 438:2015.
7. Babu S., Bennett J., Binks R., Fee P., Fox B., Johnston A., \& Tighe S., (2016): Association of Anesthetists of Great Britain and Ireland: Safe vascular access 2016. Anesthesia, 71(5), 573-585.).

8. Center of Disease Control, (2011): Guidelines for the Prevention of Intravascular CatheterRelated Infections, 111(2) Pages last updated: April 1, 2010, Page last reviewed: February 7, 2011.

9. Coyne I., Comiskey C., Lalor, J., Higgins A., Elliott N., \& Begley C., (2016): An exploration of clinical practice in sites with and without clinical nurse or midwife specialists or advanced nurse practitioners, in Ireland. BMC health services research, 16(1), 151.

10. Cooper M., (2019): Improving Nurses' Knowledge of Central Line-Associated Bloodstream Infection., Walden Dissertations and Doctoral Studies, Walden University scholar orks) p40, 47.

11. Gahlot R., Nigam C., Kumar V., Yadav G., \& Anupurba S., (2014): Catheter-related bloodstream infections. Int J Crit Illn Inj Sci 4:162-167.

12. Hill B., (2018): Role of central venous pressure (CVP) monitoring in critical care settings. Nursing Standard, 32(23).

13. Marquis L., \& Huston J., (2009): Leader ship roles and management functions in nursing, 6th ed., Lippincott, Hong Kong, pp. 371, 41-48.

14. Nickson C., (2017): critical care compendium, central venous catheters at/https://www.google.com.eg/url?sa=t\&source =web\&rct=j\&url=https://lifeinthefastlane.com/c $\mathrm{cc} /$.

15. Peduzzi M., Luiza M., Franco I., \& Benedita C., (2006): Quality of procedures delivered by nursing assistants, Saude Publica,V.(40),NO.(5),p:17-77.

16. Rosenthal J., Maki D., Jamulitrat S., Medeiros E., Todi S., \& Gomez D., (2010): International Nosocomial Infection Control Consortium report,datasummaryfor2003-2008, issuedJune2009.AmJInfectControl38:95-104.

17. Ruesch S., Walder B., \& Tramèr M., (2018): Critical Care Medicine; 30(2):454. Complications of central venous catheters: internal jugular versus subclavian access--a systematic review at https://www.uptodate.com/contents/overviewof-central-venous-access\#subscribeMessage.

18. Ullman A., Long D., \& Richard C., (2013): prevention of central venous catheter infection a 
survey of pediatric ICU nurses knowledge and practice, nurse educ today 34(2):202-7.

19. Vanstaa A., Sattoe J., \& Strating M., (2015): Experiences with and outcomes of two interventions to maximize engagement of chronically ill adolescents during hospital consultations: a mixed methods study. Journal of pediatric nursing, 30(5), 757-775.

20. Woodland D., Cooper C., Rashid M., Rosario V., Weyker P., Weintraub J., \& Kluger M., (2018): Routine $x$-ray is unnecessary after ultrasound-guided central venous line placement in the operating room. Journal of critical care, 46,13-16.

21. Zing W., Walder B., \& Pittet D., (2011): prevention of catheter related infection: toward zero risk? Curr opin infect dis.; 24(4):377-84. 